\title{
Random Walks in Daily Foreign Exchange Rates? The Case of Lebanon (2010-2015)
}

\author{
Samih Antoine Azar ${ }^{1} \&$ Tamar Kohilian ${ }^{2}$ \\ ${ }^{1}$ Professor, Faculty of Business Administration \& Economics, Haigazian University, Lebanon. \\ ${ }^{2}$ MBA graduate, Faculty of Business Administration \& Economics, Haigazian University, Lebanon. \\ Correspondence: Samih Antoine Azar, Professor, Faculty of Business Administration \& Economics, Haigazian \\ University, Mexique Street, Kantari, Beirut, Lebanon. Telefax: +9611349230.
}

Received: July 2, 2015

doi:10.11114/aef.v2i3.927
Accepted: July 17, 2015

Available online: July 22, 2015

\begin{abstract}
In most of the academic literature on asset prices, like equities or foreign exchange, the words weak-form efficiency and random walk are used interchangeably. This paper makes a distinction between these two concepts. Weak-form efficiency holds when price increments are independent and random. A random walk is more stringent: it requires that the probability distribution of price increments be identical and normal, in addition of being independent. As expected the null hypothesis of a random walk is rejected with force while the null of weak-form efficiency is not. This implies that linear filter rules, chartism, and technical analysis cannot produce abnormal profits. But this implies also that non-linear filter rules, chartism, and technical analysis can be profitable. This explains the reality of finding departments of technical analysis in most Lebanese banks. If the market experience of Lebanon is generalized to other countries this would explain why international banks also have such departments.
\end{abstract}

Keywords: daily foreign exchange rates, weak-form efficiency, random walk, independent, identical, and normal distribution, Lebanon.

\section{Introduction and Statement of the Problem}

The most important financial market in an economy is the foreign exchange market. That is why a lot of studies and research have been done in order to find ways to understand the market. One of these studies led to the Efficient Market Hypothesis (EMH).

The Efficient Market Hypothesis states that a market is efficient if all available information is used to set the price of a financial asset. The concept of Efficient Market Hypothesis has been developed independently by Samuelson (1965) and Fama $(1965,1970)$ in the 1960s. There are three broad levels of efficiency. The first is weak form efficiency whereby only past information is available. The second is the semi-strong form which extends the information set to all public information The last is the strong form efficiency which extends the information set further to include not only public information, but also private information, typically the information held by corporate insiders, such as officers and executives of the corporation.

Weak form efficiency implies that asset price increments are independent. In other terms the statistical distribution is for a process that is independent over time. In this paper weak form efficiency is distinguished from a random walk. Weak form efficiency is implied by a random walk, but the reverse is not true. For a random walk to hold price increments must not only be independently distributed but also identically and normally distributed. Hence the requirements for a random walk are tougher than the requirements for weak form efficiency. Unfortunately in the literature the two are used interchangeably, which is quite casual.

The modern foreign exchange market began forming during the 1970s after three decades of government restrictions on foreign exchange transactions with The Bretton Woods system of monetary management. The foreign exchange market is unique because of its huge trading volume, its high liquidity, its geographical dispersion, its continuous operation, the low margins of relative profit compared with other markets of fixed income, and the use of leverage to enhance profit and loss margins.

It is important to know how the foreign exchange market functions and how do exchange rates move and react. 
Accordingly the major thesis of this paper is on testing whether the Lebanese foreign exchange market follows a random walk, as defined above.

The Lebanese foreign exchange market is a free foreign exchange market, has full currency convertibility, and is free of restrictions on the inward or outward movement of capital. The Lebanese pound is convertible and its exchange rate is generally determined on the basis of demand and supply conditions in the exchange market. Bankers are allowed to engage in spot transactions in any currency. However, they are prohibited from engaging in forward transactions in Lebanese Pounds for speculative purposes. The central bank intervenes when necessary in order to maintain orderly conditions in the foreign exchange market. There are no taxes or subsidies on purchases or sales of foreign exchange.

Foreign exchange rate stability has been a primary policy objective of the Government and of the central bank. The central bank's exchange rate policy since October 1992 has been to anchor the Lebanese pound nominal exchange rate to the U.S. Dollar. As a result, the Lebanese pound exchange rate has remained unchanged since 2000. Since September 1999, the central bank has maintained its policy of pegging the value of the Lebanese Pound to the U.S. Dollar at a fixed rate averaging 1,507.5 Lebanese pound per one US dollar. The International Monetary Fund classifies the Lebanese pound as an adjustable peg to the US dollar.

\section{Literature Review}

The foreign exchange market has an important role to play in every country, and it is important to know how the market functions and how do exchange rates move and react. One celebrated theory is the Efficient Markets Hypothesis (EMH). Fama (1965, 1970, and 1991) distinguished three levels of efficiency: weak-form, semi-strong form and strong form. Each version reflects a different amount of information available to price financial assets. The weak-form of EMH asserts that prices of financial assets reflect all the information contained in past prices. Therefore, no market participant can use past data on the prices of financial assets to predict the future values of such assets. In other words, the prices of financial assets behave randomly without any discernible pattern. The semi-strong level of efficiency assumes that the information set is not only about the past but about any information in the public domain. The last level of efficiency assumes that both public and private information is already discounted in asset prices and that even insiders cannot make abnormal profits besides the fact that they can be charged legally if they trade on their private information.

Wickremasinghe (2004) tests weak and semi-strong form efficiency of foreign exchange market in Sri Lanka for six currencies, by using unit root tests, particularly the Augmented Dickey Fuller (ADF) test statistics (Dickey and Fuller, 1979, 1981). He based his research on the average monthly exchange rates of the Japanese yen, the British pound, the US dollar, the French franc, the Indian rupee and the German mark for the period January 1986 to November 2000. He found out that all exchange rates under consideration are non-stationary in their levels but become stationary when they are first differenced. The results show consistence with the weak form of the Efficient Market Hypothesis: past exchange rates cannot predict future exchange rates, and exchange rates are essentially unpredictable.

Rossi (2006) considers the issue of parameter instability in her tests for a random walk and applies tests that are robust to such parameter instability. She finds that, in general, accounting for parameter instability is capable of improving forecasts of future exchange rates.

Pukthuanthong-Le and Thomas (2008) examine currency futures for the period 1975/2006. They find in support of a learning behavior by traders: early on weak-form efficiency does not hold while later the market becomes weak-form efficient.

Ibrahim et al. (2011) study weak-form efficiency of the foreign exchange market in 30 countries of the Organization for Economic Cooperation and Development Countries. They use daily data from 2000 till 2007. In support of this level of efficiency they use the Augmented Dickey-Fuller (ADF) test, the Philip-Perron test (Phillips and Perron, 1988) and the Kwiatkowski et al. (1992) test.

Mbululu, Auret and Chiliba (2013) study whether exchange rates in Zambia are weak form efficient. They use daily exchange rates of the Zambian Kawacha against the U.S. Dollar for a period from August 2003 till December 2012. They conduct several tests like the ADF test for a unit root, Ljung-Box Q statistics for autocorrelation, variance ratio tests, as well as the Jarque-Bera test to find out if the exchange rates are normally distributed. The test results showed that the Zambian exchange market reject the EMH. The null hypothesis of homoscedasticity is rejected while the results of the Jarque-Bera test reject the null of normality.

Mohamed and Shakila (2014) study the weak form efficiency of foreign exchange markets of developing economies. They use monthly exchange rates for three major currencies (China, Indonesia, US) versus the Indian Rupee, by doing several tests like the ADF test for unit root, Jarque-Bera test for normality, and VAR tests. The results of the tests are as follows: the 3 currencies are normally distributed at $1 \%$ level, as well as they are stationary over a period of time at 5\% significant level. Hence the three exchange rates support the validity of the weak form of the efficient market hypothesis.

Kumar and Kamaiah (2014) study weak-form efficiency for nine European and emerging foreign exchange markets. Six 
markets out of the total are not found to be informationally efficient, while the other three markets are weak-form efficient only at short lags.

Azar (2014) tests whether the Lebanese foreign exchange market is weak form efficient by studying the statistical behavior of six daily foreign exchange currencies against the Lebanese pound. All series are logged and log returns are calculated by taking the first difference of the natural log. Particularly he tests whether these 6 currencies follow each a martingale. A martingale is a model of fair game, where knowledge of past events does not help to predict the future. A martingale is a sequence of random variables for which, at a particular time in the realized sequence, the expectation of the next value in the sequence is equal to the present observed value given knowledge of all prior observed values.

Azar (2014) tests whether the six currencies include one unit root, whether increments are random, whether shocks are persistent, and whether the series do not suffer from any calendar breaks. He used the following tests in his paper: unit root tests, tests on randomness and serial correlation, variance ratio tests, non-linear dependencies, normality tests, tests for breaks, ARCH tests and Granger causality tests. The data that was used in his paper were daily exchange rates for six currencies from January 4, 2010 till January 31, 2014 taken from the web site of the Bank of Lebanon.

Another test was done as well to see if there are structural breaks in the time span of the data, even though the time span was not that long. When there are structural breaks they lead the series to look like there is a unit root process while in fact there is no unit root, therefore suspicion of breaks in very important to determine for martingale hypothesis. Azar used two tests to prove that there are no breaks in the data series: the Bai-Perron test and the Quandt-Andrews unknown breakpoint test. Both tests implied the same conclusion: no breaks are found in the data series, therefore the sample is homogenous and the martingale process is an inherent feature of the data.

\section{Research Questions and Hypotheses}

Six daily foreign exchange rates against the Lebanese pounds, with 1279 observations per series, are studied. Log returns are calculated. The general hypothesis is that log returns are independently, identically, and normally distributed. The research hypotheses and the sub-hypotheses are as follows.

(a) All the six foreign exchange rates that are studied have a unit root in log-levels, and are stationary in first-differences. This is a test of weak-form efficiency. The selected test statistic is the Augmented Dickey-Fuller (ADF) test (Dickey and Fuller, 1979, 1981). This test ensures lack of predictability of the increments in log levels. Taking logs is intentional because it usually stabilizes the variance and because the first-difference of the logs is very close to a percentage change.

(b) The panel of all the six foreign exchange rates that are studied has a unit root in log-levels, and is stationary in first-differences. Six panel unit root tests are applied. Usually panel tests are more valid than individual tests because of the increased size of the sample.

(c) A stationary series with a break can be mistaken for a non-stationary series. Hence it is important to test for calendar breaks. This is tested by least squares with calendar breakpoints, by the Quandt-Andrews breakpoint tests, and by the Bai-Perron multiple breakpoint tests.

(d) The six log returns are independently distributed. This is tested by the runs tests and by the Ljung-box Q-statistics. This test is also a test of weak-form efficiency.

(e) All six log returns are identically distributed. This is tested by the Ljung-Box Q-statistics on the squares and on the absolute values of the log returns, and by the BDS independence test.

(f) All six $\log$ returns follow a normal distribution. This is tested by the skewness test, the kurtosis test, the Kolmogorov-Smirnov normality test, the Chi-square test for normality, the four EViews normality tests (Lilliefors (D); Cramer-von Mises (W2); Watson (U2); Anderson-Darling (A2)) and the Jarque-Bera normality test.

(g) All six log returns have the same zero mean and the same variance. This restricts the statistical behavior of log returns to reflect the fact that they are quoted against the same currency, the Lebanese pound, and that there are no positive or negative drifts that speculators can take advantage of.

\section{The Empirical Results}

The study will be done on 6 currencies from January 2010 till 8 April, 2015 with a daily frequency with 1279 observations per series. The six currencies are the Australian Dollar (AUD), Canadian Dollar (CAD), Swiss Franc (CHF), European Currency Unit (EURO), British Pound (GBP), and Japanese Yen (JPY). The data is taken from Bank of Lebanon's official website, and the currencies are chosen for availability and convenience. The US dollar is not taken because the exchange rate is pegged by the Bank of Lebanon. If the six foreign exchange rates follow a lognormal distribution, stated as a random walk in log levels, then this implies that the change in logs is identically, independently and normally distributed. The purpose of this paper is to test for these three characteristics: identical, independent and normal distribution. 


\subsection{Stationarity Tests}

In Table 1 the results of applying the Augmented Dickey-Fuller (ADF) test on the log-levels and log returns of the six currencies are presented. The null hypothesis is a unit root. This null fails to be rejected for the six log-level series at high marginal significance levels, the minimum such level being 0.3521. The lowest Dickey-Fuller t-statistic is -2.452424 and the highest is -1.081583 . All this is fairly strong evidence against stationarity. The same null hypothesis is tested on the $\log$ returns, i.e. the first difference of the logs. The Dickey-Fuller t-statistics are extremely negative and low, ranging between -37.94578 and -34.93936 . The actual six marginal significance levels take the values 0.0000 , which means a probability less than 0.0001 . This is fairly strong evidence for stationarity. These ADF test results corroborate the usual and common findings that asset prices have one unit root. A unit root is a prerequisite for weak form efficiency but is not sufficient for that purpose.

Table 1. Individual unit root tests with the Augmented Dickey-Fuller (ADF) test statistic. The null hypothesis is a unit root.

\begin{tabular}{|c|c|c|}
\hline Currency X & $\log X$ & $\Delta \log \mathrm{X}$ \\
\hline AUD & $-1.404169(0.8597)$ & $-36.96506(0.0000)$ \\
\hline CAD & $-1.806112(0.7015)$ & $-37.94578(0.0000)$ \\
\hline $\mathrm{CHF}$ & $-2.242003(0.4652)$ & $-34.93936(0.0000)$ \\
\hline EURO & $-1.081583(0.9303)$ & $-36.09557(0.0000)$ \\
\hline GBP & $-2.452424(0.3521)$ & $-37.76019(0.0000)$ \\
\hline JPY & $-1.800587(0.7042)$ & $-37.84230(0.0000)$ \\
\hline
\end{tabular}

Notes: The tests include a constant and a trend. The ADF t-statistics are reported. In parenthesis are the actual p-values.

Although the sample sizes are big, consisting of 1279 observations per variable, a still bigger sample may be helpful in shedding further light on the statistical process that is followed by these six currencies. That is why panel unit root tests are carried out (see Table 2), and the sample size increases six-fold to 7674. The chosen tests are obtained from Maddala and Wu (1999), Breitung (2000), Hadri (2000), Choi (2001), Levin et al. (2002), and Im et al. (2003). The null hypothesis of all these tests is for non-stationarity except for the two Hadri tests for which the null is stationarity. The lowest $\mathrm{p}$-value for the former tests on the log levels is 0.6560 , and the marginal significance levels of the same tests on the log returns are all 0.0000 , meaning that they are less than 0.0001 . This is fairly strong evidence for one unit root. This evidence is also supported by the Hadri tests which produce p-values of less than 0.0001 for the log-levels, rejecting stationarity, and a minimum p-value of 0.6760 for the log-returns failing to reject stationarity. Again this supports unequivocally one unit root, which is a necessary but not a sufficient condition for weak-form efficiency.

Table 2. Panel unit root tests.

\begin{tabular}{lcc}
\hline \multicolumn{1}{c}{ Test statistic } & log panel & $\Delta$ log panel \\
\hline \multicolumn{1}{c}{ Null: Unit root (assumes common unit root process): } & 0.0000 \\
Levin, Lin \& Chu t* & 0.6560 & 0.0000 \\
Breitung t-statistic & 0.9300 & 0.0000 \\
$\quad$ Null: Unit root (assumes individual unit root process): & 0.8853 & 0.0000 \\
Im, Pesaran and Shin W-statistic & 0.9402 & 0.0000 \\
ADF - Fisher Chi-square & 0.9383 & 0.7561 \\
PP - Fisher Chi-square & & 0.6760 \\
Null: stationarity & 0.0000 & 0.0000 \\
Hadri Z-statistic & & \\
Heteroscedastic consistent Z-statistic & & \\
\hline
\end{tabular}

Notes: Actual p-values are reported. The panel consists of the 6 foreign exchange rates (see Table 1).

\subsection{Calendar breaks}

It is known that if a stationary statistical series undergoes one or more breaks this series will look mistakenly like a non-stationary series. The purpose of this section is to test for breaks in the log returns of the six currencies. Least squares with breaks are applied on regressions on the constants for each currency. None of the six regressions produces evidence of a break. In addition, the Bai-Perron test (Bai, 1997; Bai and Perron, 1998) is applied on the six demeaned $\log$ returns. The results are in Table 3. In total 5 breaks are allowed for but none is found. To be more certain about the inexistence of breaks Quandt-Andrews unknown breakpoint tests are additionally implemented (Andrews, 1993; Andrews and Ploberger, 1994). Six different test statistics are computed, out of which 3 are reported (Table 3). In total, and for each currency, 895 break points are compared. The actual p-values are all higher than $5 \%$ except for the Japanese yen that shows some weak indication of a significant break. These test results reflect the fact that during the period considered the political, economic, and budgetary situation did not significantly change despite the occurrence of a civil war in a neighbor state, Syria, which led to the influx of more than a million refugees to Lebanon. Most of these 
refugees have little to count upon and require assistance at all levels. As such they are a drag on the water, electrical, sanitary, housing, educational, medical and other resources of Lebanon, besides competing in the workplace for jobs that Lebanese lose for them. It is estimated that there are two millions of Syrians in Lebanon, which is originally a home for just four millions of Lebanese.

Table 3. Tests for calendar breakpoints on $\Delta \log \mathrm{X}$, i.e. the log returns.

\begin{tabular}{|c|c|c|c|c|c|}
\hline \multirow[b]{2}{*}{ Currency } & \multirow[b]{2}{*}{ Least squares with breaks } & \multicolumn{3}{|c|}{$\begin{array}{l}\text { Quandt-Andrews unknown breakpoint test } \\
\text { (Wald F-statistic) }\end{array}$} & \multirow{2}{*}{$\begin{array}{l}\text { Bai-Perron Multiple } \\
\text { breakpoint tests } \\
\text { (5\% critical value of } \\
\text { F-statistic: } 8.58)\end{array}$} \\
\hline & & Maximum & $\operatorname{Exp}$ & Ave & \\
\hline AUD & No breakpoints selected & 0.3600 & 0.1586 & 0.0988 & 4.097838 \\
\hline CAD & No breakpoints selected & 0.5837 & 0.2666 & 0.1864 & 2.859598 \\
\hline $\mathrm{CHF}$ & No breakpoints selected & 0.1456 & 0.5354 & 0.5967 & 6.227464 \\
\hline EURO & No breakpoints selected & 0.1667 & 0.2202 & 0.3267 & 5.917699 \\
\hline GBP & No breakpoints selected & 0.4875 & 0.7519 & 0.8115 & 3.335263 \\
\hline JPY & No breakpoints selected & 0.0542 & 0.0215 & 0.0171 & 8.432660 \\
\hline
\end{tabular}

Notes: Actual p-values for the Quandt-Andrews test are reported, its null hypothesis is no breakpoint, and 895 breaks are compared. The actual F-value is reported for the Bai-Perron test, and its null hypothesis is no breakpoint.

\subsection{Randomness and independence}

In Table 4 independence tests on the log returns are carried out. Two tests are chosen, which are the tests commonly applied in the literature. These are the runs test and the Ljung-Box Q-statistic. Both tests have the same null hypothesis: randomness and independence. The runs test can be computed on the mean and on the median. In the first case the lowest actual p-value is 0.164 , and in the second it is 0.083 . The highest p-value is 0.990 for the first test and 0.942 for the second. This is strong evidence for randomness and independence.

A unit root in log-level variables and stationarity in log returns do not eliminate the presence of autocorrelation. In fact the $\mathrm{ADF}$ test includes usually lagged values of the dependent variable, the log returns. That is why there is a need to test for time series independence of $\log$ returns. The actual p-values of the ljung-Box Q-statistics are reported in Table 4. Three lag lengths are adopted. Since the data is daily these lag lengths are chosen to be 5, 10, and 15 days. Seventeen out of a total of eighteen p-values are higher than 5\%, failing to reject independence. One p-value is equal to 0.032 for lag length 15 for the CAD. This should not be of major concern.

Since all six series are found to be random and autocorrelations are statistically insignificant then this is strong evidence for weak form efficiency. However as mentioned previously the purpose of this paper is to test for a random walk. A random walk is defined for an independent, identical, and normal distribution. Weak form efficiency conforms to the first condition only, which is independence. Researchers usually stop at this point of the analysis and refrain from testing for an identical and normal distribution. It can be shown that if a series is not identically and normally distributed arbitrage profits can still be made.

Table 4. Tests of randomness and serial independence on $\Delta \log X$, i.e. the $\log$ returns.

\begin{tabular}{lccccc}
\hline \multicolumn{1}{c}{ Currency X } & Runs test on the mean & Runs test on the median & \multicolumn{3}{c}{ Ljung-Box Q-statistic } \\
\cline { 4 - 6 } & & & $\mathrm{K}=5$ & $\mathrm{~K}=10$ & $\mathrm{~K}=15$ \\
\hline AUD & 0.912 & 0.695 & 0.918 & 0.535 & 0.073 \\
CAD & 0.502 & 0.942 & 0.086 & 0.101 & 0.032 \\
CHF & 0.164 & 0.083 & 0.178 & 0.053 & 0.204 \\
EURO & 0.990 & 0.871 & 0.621 & 0.476 & 0.430 \\
GBP & 0.647 & 0.908 & 0.349 & 0.710 & 0.623 \\
JPY & 0.883 & 0.883 & 0.388 & 0.398 & 0.377 \\
\hline
\end{tabular}

Notes: Actual p-values are reported for all tests. The null of the runs tests is randomness. The null of the Ljung-Box Q-statistic is independent increments. The symbol k stands for the lag length in the computation of the Q-statistic.

\subsection{Non-Linear Dependence}

Non-linear independence is tested in Table 5. Three test results are reported: the Ljung-Box Q-statistic on the squares and on the absolute values of the log returns, and the BDS independence test (Brock et al., 1996). Since daily returns are very small, and are insignificantly different from zero, as will be seen below, then there is no need to subtract the mean return before squaring or taking the absolute values. All three tests have the same null hypothesis which is absence of non-linear dependence. The first two tests are variants of the ARCH test, and measure the existence of conditional heteroscedasticity. 
For these two tests the same three lag length are chosen: 5, 10, and 15 days. The 54 ( 6 by 9) actual p-values are all lower than 0.001. Non-linear dependence fails to be rejected. This means that the variance is not constant and the identical condition for the distribution of the log returns is not satisfied. This implies that non-linear technical analysis can be profitable.

Table 5. Tests for conditional heteroscedasticity and non-linear dependence of $\Delta \log \mathrm{X}$, i.e. the $\log$ returns.

\begin{tabular}{lccccccccr}
\hline & \multicolumn{3}{c}{$\begin{array}{c}\text { Ljung-Box Q-statistic on the } \\
\text { absolute value of } \Delta \log \mathrm{X}\end{array}$} & \multicolumn{2}{c}{$\begin{array}{c}\text { Ljung-Box Q-statistic on the square } \\
\text { of } \Delta \log \mathrm{X}\end{array}$} & \multicolumn{3}{c}{$\begin{array}{c}\text { BDS independence test } \\
\text { with dimension: }\end{array}$} \\
\cline { 2 - 10 } Currency X & $\mathrm{K}=5$ & $\mathrm{~K}=10$ & $\mathrm{~K}=15$ & $\mathrm{~K}=5$ & $\mathrm{~K}=10$ & $\mathrm{~K}=15$ & 2 & 4 & 6 \\
\hline AUD & 0.000 & 0.000 & 0.000 & 0.000 & 0.000 & 0.000 & 0.0008 & 0.0000 & 0.0000 \\
CAD & 0.000 & 0.000 & 0.000 & 0.000 & 0.000 & 0.000 & 0.0004 & 0.0000 & 0.0000 \\
CHF & 0.000 & 0.000 & 0.000 & 0.000 & 0.000 & 0.000 & 0.0000 & 0.0000 & 0.0000 \\
EURO & 0.000 & 0.000 & 0.000 & 0.000 & 0.000 & 0.000 & 0.0001 & 0.0000 & 0.0000 \\
GBP & 0.000 & 0.000 & 0.000 & 0.000 & 0.000 & 0.000 & 0.0004 & 0.0000 & 0.0000 \\
JPY & 0.000 & 0.000 & 0.000 & 0.000 & 0.000 & 0.000 & 0.0001 & 0.0000 & 0.0000 \\
\hline
\end{tabular}

4.5 Normality Tests

Seven normality tests are applied on the six series of log returns (Table 6). The Jarque-Bera test is the best known, and tests jointly for skewness and kurtosis. Both characteristics, skewness and kurtosis, are apparent in the six series, as evidenced by the actual z-statistics in Table 7. Four tests are retrieved from the EViews application, and two tests are non-parametric (the chi-square and the Kolmogorov-Smirnov tests). Non-parametric tests are free of distributional assumptions, and hence can give a differential result. For all tests the null hypothesis is normality. The actual p-values are all lower than 0.01 , providing strong support for the alternative hypothesis, which is non-normality. Here again speculation can take advantage of non-normality by appropriate financial positions. The simplest such arbitrage is by taking advantage of the fact that all six distributions are skewed. For example a long position may provide abnormal long run profits if the distribution is skewed to the right. If the distribution is skewed to the left a short position is profitable in the long run. Therefore both skewness and kurtosis can make technical analysis profitable and worthwhile.

Table 6. Normality tests on $\Delta \log \mathrm{X}$, i.e. the $\log$ returns.

\begin{tabular}{cccccccc}
\hline $\begin{array}{c}\text { Currency } \\
\text { X }\end{array}$ & Jarque-Bera & $\begin{array}{c}\text { Lilliefors } \\
(\mathrm{D})\end{array}$ & $\begin{array}{c}\text { Cramer-von } \\
\text { Mises (W2) }\end{array}$ & $\begin{array}{c}\text { Watson } \\
(\mathrm{U} 2)\end{array}$ & $\begin{array}{c}\text { Anderson-Darling } \\
(\mathrm{A} 2)\end{array}$ & $\begin{array}{c}\text { Chi-square } \\
\text { test }\end{array}$ & KS test \\
\hline AUD & 0.0000 & 0.0000 & 0.0000 & 0.0000 & 0.0000 & 0.0000 & 0.006 \\
CAD & 0.0000 & 0.0000 & 0.0000 & 0.0000 & 0.0000 & 0.0000 & 0.000 \\
CHF & 0.0000 & 0.0000 & 0.0000 & 0.0000 & 0.0000 & 0.0000 & 0.000 \\
EUR & 0.0000 & 0.0000 & 0.0000 & 0.0000 & 0.0000 & 0.0000 & 0.000 \\
GBP & 0.0000 & 0.0000 & 0.0000 & 0.0000 & 0.0000 & 0.0031 & 0.004 \\
JPY & 0.0000 & 0.0000 & 0.0000 & 0.0000 & 0.0000 & 0.0000 & 0.000 \\
\hline
\end{tabular}

Notes: The KS test is the Kolmogorov-Smirnov non-parametric test. Actual p-values for all tests are reported. The null is normality for all tests.

\subsection{Descriptive Statistics and Hypothesis Tests}

In Table 7 descriptive statistics are presented on all six $\log$ returns. Since all skewness tests denote the presence of left-tailed or negatively skewed distributions, the median is a better measure of central tendency than the mean. The six medians are close to zero, their maximum being 0.000113 , and four out of the rest being less than 0.00001 . Eviews 8.1 computes 5 test statistics for the equality of medians across the six currencies. The null hypothesis, which is for equality of medians, fails to be rejected with actual p-values ranging between 0.3737 and 0.9698 , depending on the test statistic. There are two F-tests for the null of equality of means, one of which allows for unequal variances. The actual p-values are 0.9060 and 0.9301 , failing to reject the null of equality. Table 8 presents the t-tests on the six mean log returns for the null that each one is zero. The six means are insignificantly different from zero, with the smallest actual p-value being 0.2259. The implication of a zero mean and a zero median is that speculators cannot earn abnormal profits in the long run, with a buy and hold position, simply because there is neither a positive nor a negative drift. The kurtosis tests show distributions with severe leptokurtosis. Assuming 250 open days a year the yearly standard deviations are obtained by multiplying the daily ones with the square root of 250 . The range of these annual standard deviations is between 0.08103 , for the British pound, and 0.12796 for the Swiss franc. One would expect the variances to be equal because the underlying currency is the same. However three tests for equality of variances between series reject the null of equality with actual p-values less than 0.0001. In Table 9 pair-wise F-tests on the variances are conducted. Only the variances of the Euro and the Japanese yen are found to be equal. This finding corroborates the evidence in Azar (2013) on monthly data whereby each currency follows a different probability density. 
Table 7. Descriptive statistics on $\Delta \log X$, i.e. the $\log$ returns.

\begin{tabular}{lcccccccc}
\hline $\begin{array}{c}\text { Currency } \\
\text { X }\end{array}$ & mean & median & max & min & $\begin{array}{c}\text { Standard } \\
\text { deviation }\end{array}$ & $\begin{array}{c}\text { Annual } \\
\text { st. dev. }\end{array}$ & $\begin{array}{c}\text { Skewness } \\
\text { test }\end{array}$ & $\begin{array}{c}\text { Kurtosis } \\
\text { test }\end{array}$ \\
& & & & & & & & \\
& & & & & & & & \\
\hline AUD & -0.000125 & 0.0000958 & 0.030186 & -0.04226 & 0.007485 & 0.11835 & -5.103 & 16.92 \\
CAD & -0.000140 & 0.000000 & 0.027628 & -0.03281 & 0.005548 & 0.08772 & -4.397 & 17.85 \\
CHF & 0.0000577 & 0.000113 & 0.149415 & -0.07587 & 0.008093 & 0.12796 & -15.833 & 119.41 \\
EURO & -0.000220 & 0.000000 & 0.020842 & -0.03430 & 0.006037 & 0.09545 & -6.382 & 12.29 \\
GBP & -0.0000643 & 0.000000 & 0.024694 & -0.02902 & 0.005125 & 0.08103 & -5.103 & 16.44 \\
JPY & -0.000199 & 0.000000 & 0.027992 & -0.03714 & 0.006038 & 0.09547 & -7.118 & 32.55 \\
\hline
\end{tabular}

Notes: The actual z-statistics are reported for the skewness and kurtosis tests. The null hypotheses are absence of skewness and absence of kurtosis. The critical values for these two tests at the $5 \%$ marginal significance level are \pm 1.96 . The annual standard deviation is equal to the daily standard deviation multiplied by the square root of 250 days a year.

Table 8 . Independent sample t-tests. The null hypothesis is that the average log return is zero

\begin{tabular}{cc}
\hline AUD & $-0.000125(0.5427)$ \\
CAD & $-0.000140(0.3078)$ \\
CHF & $0.0000577(0.7962)$ \\
EURO & $-0.000220(0.1988)$ \\
GBP & $-0.0000643(0.6441)$ \\
JPY & $-0.000199(0.2259)$ \\
\hline
\end{tabular}

Notes: two-tailed actual p-value in parenthesis.

Table 9. F-tests of equality of variance. Actual F-values are reported.

\begin{tabular}{llllll}
\hline & CAD & CAD & CHF & EURO & \\
CAD & 1.820 & & & & \\
CHF & 1.169 & 2.128 & 1.797 & & \\
EURO & 1.537 & 1.184 & 2.493 & 1.388 & 1.388 \\
GBP & 2.133 & 1.172 & 1.797 & 1.000 & \\
JPY & 1.537 & 1.184 & & & \\
\hline
\end{tabular}

Notes: The critical values are $1.10(5 \%), 1.12(2.5 \%)$, and $1.14(1 \%)$.

\section{Conclusion}

This paper studies the probability distribution of daily foreign exchange rates in Lebanon for the recent five years. It is stated that the random walk hypothesis requires more than just weak-form efficiency. A random walk implies that the probability distribution of price increments be identical and normal, and not only independent. With such stringier conditions the random walk hypothesis is rejected with force, while weak-form efficiency is not. If prices do not follow a random walk, abnormal profits can be made by taking appropriate positions in the financial market. In such a case speculation, like non-linear filter rules, non-linear chartism, and non-linear technical analysis, is profitable. This would explain the fact why every big Lebanese bank has a department where technical analysis is performed on foreign exchange rates. Foreign banks are also not immune from this exercise and they spend money and resources on technical analysis. This suggests that the random walk hypothesis is rejected in other foreign exchange markets, even those that include developed countries.

\section{References}

Andrews, D. W. K. (1993). Tests for parameter instability and structural change with unknown change point. Econometrica, 61. 821-856. http://dx.doi.org/10.2307/2951764

Andrews, D. W. K., \& Ploberger, W. (1994). Optimal tests when a nuisance parameter is present only under the alternative. Econometrica, 62, 1383-1414. http://dx.doi.org/10.2307/2951753

Azar, S. (2013). The post-war behavior of foreign exchange rates in Lebanon. The Empirical Economics Letters, 12(9), 1005-1010.

Azar, S. (2014). Martingale in daily foreign exchange rates: evidence from six currencies against the Lebanese pound. Applied Economics and Finance, 1(1), 55-64.

Bai, J. (1997). Estimating multiple breaks one at a time. Econometric Theory, 13, 315-352. http://dx.doi.org/10.1017/S0266466600005831

Bai, J., \& Perron, P. (1998). Estimating and testing linear models with multiple structural changes. Econometrica, 66, 47-78. http://dx.doi.org/10.2307/2998540

Breitung, J. (2000). The local power of some unit root tests for panel data. In B. Baltagi (ed.), Advances in Econometrics, 15, Nonstationary Panels, Panel Cointegration, and Dynamic Panels, Amsterdam: JAI Press, 161-178. http://dx.doi.org/10.1016/S0731-9053(00)15006-6 
Brock, W., Dechert, D., Sheinkman, J., \& LeBaron, B. (1996). A test for independence based on the correlation dimension. Econometric Reviews, 15, 197-235. http://dx.doi.org/10.1080/07474939608800353

Choi, I. (2001). Unit root tests for panel data. Journal of International Money and Finance, 20, $249-272$. http://dx.doi.org/10.1016/S0261-5606(00)00048-6

Dickey, D. A., \& Fuller, W. A. (1979). Distribution of the estimators for autoregressive time series with a unit root. Journal of the American Statistical Association, 74(366a), 427-431. http://dx.doi.org/10.2307/2286348. http://dx.doi.org/10.1080/01621459.1979.10482531

Dickey, D. A., \& Fuller, W. A. (1981). Likelihood ratio statistics for autoregressive time series with a unit root. Econometrica, 1057-1072. http://dx.doi.org/10.2307/1912517

Fama, E. (1965). The Behavior of Stock-Market Prices. Journal of Business, 38(1), 34-105. http://dx.doi.org/10.1086/294743

Fama, E. (1970). Efficient capital markets: a review of theory and empirical work, Journal of Finance, 25(2), $383-417$. http://dx.doi.org/10.2307/2325486. http://dx.doi.org/10.1111/j.1540-6261.1970.tb00518.x

Fama, E. (1991). Efficient capital markets II, Journal of Finance, 46(5), 1575-1617. http://dx.doi.org/10.1111/j.1540-6261.1991.tb04636.x

Hadri, K. (2000) Testing for stationarity in heterogeneous panel data. Econometric Journal, 3, 148-161. http://dx.doi.org/10.1111/1368-423X.00043

Ibrahim, H., Long, Y., Ghani, H. A., \& Salleh, S. I. M. (2011). Weak-form efficiency of foreign exchange market in the Organization for Economic Cooperation and Development countries: unit root test. International Journal of Business and Management, 6(6), 55-65. http://dx.doi.org/10.5539/ijbm.v6n6p55

Im, K. S., Pesaran, M. H., \& Shin, Y. (2003). Testing for unit roots in heterogeneous panels. Journal of Econometrics, 115, 53-74. http://dx.doi.org/10.1016/S0304-4076(03)00092-7

Kumar, A. S.., \& Kamaiah, B. (2014). Efficient market hypothesis: some Evidences from emerging European forex markets. The Romanian Economic Journal, 52, 27-43.

Kwiatkowski, D., Phillips, P. C. B., Schmidt, P., \& Shin, Y. (1992). Testing the null hypothesis of stationarity against the alternative of a unit root. Journal of Econometrics, 54, 1-3, 159-178. http://dx.doi.org/10.1016/0304-4076(92)90104-Y

Levin, A., Lin, C.F. \& Chu, C. (2002) Unit root tests in panel data: asymptotic and finite-sample properties. Journal of Econometrics, 108, 1-24. http://dx.doi.org/10.1016/S0304-4076(01)00098-7

Maddala, G. S., \& Wu, S. (1999). A comparative study of unit root tests with panel data and a new simple test. Oxford Bulletin of Economics and Statistics, 61, 631-652. http://dx.doi.org/10.1111/1468-0084.61.s1.13

Mbululu, D., Auret, C. J., \& \& Chiliba, L. (2013). Do exchange rates follow random walks? A variance ratio test of the Zambian foreign exchange market; Southern African Business Review, 17(2), 45-62.

Mohamed, M., \& Shakila, M. A. (2014). Study on weak-form efficiency of foreign exchange markets of developing economies: some India evidence. International Journal of Management, 6(1), 331-342.

Phillips, P. C. B., \& Perron, P. (1988). Testing for a unit root in time series regression. Biometrika, 75(2), $335-346$. http://dx.doi.org/10.1093/biomet/75.2.335

Pukthuanthong-Le, K., \& Lee T., (2008) Weak-Form Efficiency in Currency Markets, Financial Analysts Journal, 64(3), 31-52. http://dx.doi.org/10.2469/faj.v64.n3.5

Rossi, B. (2006) Are exchange rates really random walks? Some evidence robust to parameter instability. Macroeconomic dynamics, 10(1), 20-38. http://dx.doi.org/10.1017/s1365100506050085

Samuelson, P. A. (1965). Proof that properly anticipated prices fluctuate randomly. Industrial Management Review, 6(2), 41-49.

Wickremasinghe, G. B. (2004). Efficiency of foreign exchange markets: A developing country perspective. Available at SSRN 609285. http://dx.doi.org/10.2139/ssrn.609285

\section{$(\mathrm{cc}) \mathrm{Br}$}

This work is licensed under a Creative Commons Attribution 3.0 License 